\title{
Development and validation of a new method for visual acuity assesment on tablet in pediatric population: eMOVA test
}

NOEMIE STOLL ( $\square$ noemstoll@gmail.com )

Hopitaux Civils de Colmar

Claude SPEEG-SCHATZ

Hopitaux universitaires de Strasbourg

Elsa Di Foggia

Hopitaux Civils de Colmar

Arnaud Sauer

Hopitaux universitaires de Strasbourg

Research article

Keywords: Amblyopia, visual screening, visual acuity, pediatrics ophthalmology, child, eMOVA test, tablet

Posted Date: April 6th, 2020

DOI: https://doi.org/10.21203/rs.3.rs-18473/v1

License: (c) (i) This work is licensed under a Creative Commons Attribution 4.0 International License.

Read Full License 


\section{Abstract}

Background Amblyopia is a major public health problem. Its screening and management require reliable methods of assessing visual acuity. Many tests are available, some of which are used as a reference and the advent of new technologies sees many others whose validity is not proven. The objective of our study was to develop a tablet-based visual acuity test adapted to the pediatric population: the eMOVA test (electronic Measurement Of Visual Acuity).

Methods We did a study comparing the eMOVA test with the Rossano-Weiss test. All children aged 3 to 8 attending the ophthalmic and pediatric consultation between September 2016 and June 2017 were included. The results in terms of visual acuity were compared as well as the duration of each test, its comprehension, its acceptability and the attention of the child during the test.

Results The eMOVA test overestimated visual acuity by 0.06 logMAR. This difference, statistically significant, was not clinically relevant. The duration of the eMOVA test was longer than the reference test, but it was less painful and more appreciated by children and their parents.

Conclusion The e-MOVA test appears as a reliable method of assessing visual acuity that could be used both in consultation and on a larger scale in the context of screening as well as for the care of the most difficult children.

\section{Background}

Amblyopia and refractive abnormalities are the two leading causes of preventable visual impairment in children. Arnold et al. have shown that one in 40 preschool children have amblyopia with visual acuity less than 20/40 and that one in five children has a risk factor for amblyopia (1).

Most causes of amblyopia are treatable, provided they have been detected early enough.

Indeed, there is a so-called "sensitive" period during which the maturation of the visual pathways of the child is not completed. Proper management of amblyopia before the end of this period can make it disappear or at least reduce its depth. Effective screening for these disorders is therefore necessary and should be as early as possible. This screening, which is a public health priority, requires assessment methods adapted to the child and the disorders sought, from mass screening to specialist consultation of ophtalmo-pediatrics.

The methods of assessing the visual acuity of the child are numerous and varied. None meet the characteristics of an ideal test, defined as follow angular acuity, logarithmic progression scale, space between optotypes = size of optotype, space between lines = size of optotype, sufficient and odd number of optotypes (five), confusion's letter at the beginning and the end, luminance $150-650 \mathrm{~cd} / \mathrm{m}^{2}$, Contrast > $70 \%(8-10)$. 
The growing craze for new technologies in the medical field is pushing us to evolve. In 2011, WHO defined the term "mHealth" as a medical and public health practice supported by mobile devices such as mobile phones, patient monitors, PDAs, and other wireless devices. In ophthalmology, digital applications have developed with diabetes (2) and AMD (3), with the development of adapters for photographs of the anterior and posterior segments (4), the study of contrast sensitivity and color vision $(5,6)$. Because of their portability, these new technologies are particularly interesting for improving eye health in developing countries (7). In the field of ophtalmo-pediatrics, some authors have proposed a binocular approach to amblyopia with rehabilitation exercises in the form of games on iPad with encouraging results. The new technologies are constantly improving and could allow us to overcome these technical difficulties. In addition, their growing appeal to the pediatric population makes it a real advantage.

The objective of our study was to develop a tablet application that reliably assesses children's visual acuity in order to provide an effective tool for screening visual disorders.

\section{Methods}

\section{eMOVA test and gold standard}

We have developed a visual acuity test on tablet: eMOVA test (electronic Measurement Of Visual Acuity) developed in near vision in a first version. We developed a method by pairing with Raskin's E (Figure 1). This choice was motivated by the desire to be able to use the same optotype with the eMOVA test and the Rossano-Weiss test. In addition, it allows a measure of angular visual acuity.

\section{Distance of realization of the test}

We kept a distance of $40 \mathrm{~cm}$ between the eyes of the child and the screen of the tablet. Since accommodation is dependent on reading distance, it is very important to adopt a fixed distance when assessing near visual acuity. The American Academy of Ophthalmology recommends a distance of 35 to $40 \mathrm{~cm}$ for assessing visual acuity. When a child watches a test at a distance he chooses himself (between 5 and $20 \mathrm{~cm}$ ), the visual acuity measured decreases by 0.15 logMAR compared to the visual acuity measured at $40 \mathrm{~cm}$. At $40 \mathrm{~cm}$, the influence of accommodation is minimal. This distance makes it easier to compare near and far visual acuity measurements. There is no evidence for a near and far difference in visual acuity in children with normal or reduced vision when the distance of $40 \mathrm{~cm}$ is respected. From the age of 4 , children are very good at keeping this distance when measuring near vision (11).

\section{Study design}

We carried out a single-centric study comparing the evaluation of visual acuity by the eMOVA test against the Rossano-Weiss reference test. Both tests were conducted blindly by two different stakeholders during 
the same consultation. The inclusion criteria were:

- Child aged 3 to 8 years

- Child able to express his agreement to the tests and parent or legal representative who has given his consent

The exclusion criteria were:

- Patients who have already performed the eMOVA test once

- Patients with a disability suggesting that subjective assessment of visual acuity is not possible

The primary endpoint was the measurement of visual acuity presented in log and decimal notation.

The secondary endpoints were:

- The understanding of the test

- The child's attention when carrying out the test

- The respect of the distance of realization of the test

- The duration of the test

- The hardness of the test

The understanding of the test, the child's attention and respect for distance were subjectively evaluated from 0 to 5 by the examiner.

The duration of the test was measured using a stopwatch and the difficulty of the test was assessed using the FLACC scale.The duration of use of a tablet or smartphone at home and the number of previous consultations were also collected. The study and data collection conformed to all local laws and were compliant with the principles of the Declaration of Helsinki. Local institutional review board approved our study.

\section{Statistical analysis}

The analysis of the results was carried out in several stages.First, we calculated the average visual acuity obtained with each of the two tests as well as the average difference in visual acuity obtained between the two tests for each patient.In a second step, to test the equivalence of the two visual acuity tests, we carried out a concordance study for the analysis of the main judgment criterion. The concordance analyzes for the quantitative variables were performed graphically using the Bland \& Altman method and calculating the intra-class correlation coefficient (ICC). For qualitative variables, the concordance was 
evaluated by calculating the Kappa coefficient. The $95 \%$ confidence intervals of these two indicators were calculated using a bootstrap resampling method.Third, a superiority study was conducted for the analysis of secondary endpoints. She compared the quantitative variables using the Wilcoxon signed rank test and the qualitative variables using the Bhapkar test.A sequence effect was tested by comparing visual acuity according to the sequence of realization using a signed rank test of Wilcoxon.A p-value $<0.05$ was considered statistically significant. The analyzes were performed using $R$ version 3.2.2 software

\section{Results}

\section{Patients characteristics}

One hundred patients were included between September 2016 and June 2017. The average age was 68 months. Four children were excluded from the analyzes because they could not perform the tests. Patient characteristics are presented in Table 1. 
Table 1

Patients characteristics

\begin{tabular}{|c|c|}
\hline Criteria collected & Number \\
\hline \multicolumn{2}{|l|}{ Age : (in months) } \\
\hline - Between 36 and 59 & $28 \%$ \\
\hline - Between 60 and 66 & $22 \%$ \\
\hline - Between 67 and 79 & $23 \%$ \\
\hline - Between 80 and 112 & $24 \%$ \\
\hline \multicolumn{2}{|l|}{ Sexe : } \\
\hline - Girls & $56 \%$ \\
\hline - Boys & $44 \%$ \\
\hline \multicolumn{2}{|l|}{ Number of consultations préalables } \\
\hline - First consultation & $16 \%$ \\
\hline - Between 1 and 5 & $38 \%$ \\
\hline - Between 6 and 10 & $21 \%$ \\
\hline$->10$ & $25 \%$ \\
\hline \multicolumn{2}{|l|}{ Reason for consultation } \\
\hline - Screening & $25 \%$ \\
\hline - Amblyopia or known risk factor of amblyopia & $75 \%$ \\
\hline Known amblyopia & $12 \%$ \\
\hline Strabismus & $34 \%$ \\
\hline Hypermétropia & $22 \%$ \\
\hline Astigmatism & $10 \%$ \\
\hline Myopia & $4 \%$ \\
\hline \multicolumn{2}{|c|}{ Duration of use of a smartphone or tablet at home per week } \\
\hline$-<3$ hours & $62 \%$ \\
\hline - between 3 and 7 hours & $22 \%$ \\
\hline - between 7 and 14 hours & $13 \%$ \\
\hline - > 14 hours & $3 \%$ \\
\hline
\end{tabular}




\section{Main outcome (Table 2)}

The average visual acuity obtained with the Rossano-Weiss test was -0.22 logMAR or $6.2 / 10$ for the right eye and $-0.24 \operatorname{logMAR}$ or $6.1 / 10$ for the left eye. The mean visual acuity obtained with the eMOVA test was $-0.28 \log M A R$ or $5.9 / 10$ for the right eye and $-0.24 \log M A R$ or $6.1 / 10$ for the left eye. The mean difference in visual acuity between the two groups was -0.06 logMAR or $0.3 / 10$ for the right eye and 0.00 logMAR or $0 / 10$ for the left eye. The maximum visual acuity obtained was -0.18 logMAR for both tests. The minimum visual acuity achieved was $-0.67 \log M A R$ and $-1.2 \log M A R$, respectively, for the RossanoWeiss test and the eMOVA test. The first quartile, median, third quartile and mode were -0.18 logMAR for all groups.

Overall, the differences in visual acuity measured by the two tests are very limited. In order to test the equivalence of the two tests, a statistical analysis of concordance was conducted.

For this analysis, we studied two sets of values to verify the validity of our results: the first on the right eye and the second on the left eye of each patient.

The correlation coefficient $r$, of the visual acuity measurement with the Rossano-Weiss test and the eMOVA test was 0.40 ( $p<0.001$ and $95[0.21-0.55])$ for the right eye series and $0.43(p<0.001$ and IC 95 $[0.26-0.58])$ for the left eye series. Ninety-one percent (91\%) of the right eyes, whose visual acuity measured with the Rossano-Weiss test was - 0.18 logMAR, achieved the same visual acuity with the eMOVA test (respectively $95 \%$ and 0.18 logMAR for left eyes). The average difference between the two tests was - 0.06 logMAR (lower bound: -0.48 , upper bound 0.36 ) for the right eye series and -0.01 logMAR (lower bound: -0,40, upper bound: 0.38 ) for the left eye series.

Table 2

Main results

\begin{tabular}{|lll|}
\hline & Right eye series & Left eye series \\
\hline $\begin{array}{l}\text { Average visual acuity } \\
\text { (in logMAR) }\end{array}$ & & \\
\hline - Rossano-Weiss test & -0.22 & -0.24 \\
\hline - eMOVA test & -0.28 & -0.24 \\
\hline Average difference between the two tests & $-0.06[-0.48-0.36]$ & $-0.01[-0.40-0.38]$ \\
\hline p & $0.006[-0.10-0.02]$ & $0.006[-0.10-0.02]$ \\
\hline Correlation coefficient & 0.40 & 0.43 \\
\hline
\end{tabular}

On the Bland and Altman analysis (Fig. 1), the concordance is very good for the highest visual acuities and from - $0.6 \log M A R$, the concordance becomes less good. The eMOVA test overestimated the visual acuity of the lowest acuities. 
The eMOVA test overestimated the visual acuity of $0.06 \log M A R$ for the right eye series and $0.01 \log M A R$ for the left eye series.

Using the lower and upper limits, we find that at most the difference in values obtained between the two tests was $-0.48 \log$ MAR for the right eye series (Fig. 2) and - $0.40 \log$ MAR for the left eye series (Fig. 3).

The average difference between the two measurements was - 0.06 logMAR in favor of the eMOVA test using the Wilcoxon test. This difference was statistically significant $(p=0.006)$. The $95 \%$ confidence interval of this difference was [-0.10-0.02]. These results were the same for both series. This means that at most, the difference in visual acuity measured between the two tests would be $0.10 \log$ MAR.

The results of the two concordance and superiority tests show the same trend: the eMOVA test statistically significantly overestimates visual acuity. This difference, however, is not clinically relevant as it would be at most 0,06 logMAR.

Analysis of the Bland and Altman graphs shows that measurement concordance decreases for low visual acuity. The concordance is good for the visual acuities between 0 and $-0.6 \log$ MAR and becomes lower for the visual acuities lower than - $0.6 \log$ MAR (Fig. 2). This trend is also found for the second series (Fig. 3).

\section{Secondary judgment criteria}

The results are shown in Table 3.

Eighty-four percent (84\%) of all children had an understanding score of 5 . Eighty-one percent $(81 \%)$ of all children had an attention score of 5 . Eighty-four percent $(84 \%)$ of all children had a distance score greater than or equal to 4 . There was no statistically significant difference between the two tests.

The average difference in duration of assessment of visual acuity in both eyes between the two tests is 21 seconds. The minimum duration is 11 seconds for the Rossano-Weiss test and 23 seconds for the eMOVA test. The maximum duration is 340 seconds for the Rossano-Weiss test and 174 seconds for the eMOVA test. These differences are statistically significant $(p<0.001)$.

Overall, for both tests, we notice that the child's discomfort increases during the test. The average FLACC scores obtained before / during / after the test were all three lower with the eMOVA test. The eMOVA test is less painful for the child than the Rossano-Weiss test and this difference is statistically significant $(p=$ 0.01). 
Table 3

Comparison of secondary judgment criteria.

\begin{tabular}{|llll|}
\hline & Rossano-Weiss & eMOVA & p \\
\hline Understanding & 4.8 & 4.8 & 0.11 \\
\hline Attention & 4.7 & 4.8 & 0.26 \\
\hline Respect of distance & 4.4 & 4.3 & 0.72 \\
\hline Duration & 43 & 64 & $<0.001$ \\
\hline Total FLACC & 0.3 & 0.1 & 0.01 \\
\hline
\end{tabular}

\section{Test parameters}

The reproducibility of the eMOVA test was calculated on a sample of 30 eyes that performed the eMOVA test twice in a row under identical conditions. The reproducibility of the eMOVA test was very good with an intra class correlation coefficient of 0.93 (95\% $\mathrm{Cl}$ [0.87-0.97]). The sensitivity of the eMOVA test was $56 \%$ and its specificity $88 \%$. The negative predictive value of the test was $90 \%$ and its positive predictive value $53 \%$. The accuracy of the eMOVA test was $82 \%$.

\section{Choice of preferred test}

The eMOVA test was mostly chosen by parents and children. Eighty-seven percent (87\%) of the children and $80 \%$ of the parents chose the eMOVA test.

\section{Sequence effect}

No sequence effect was highlighted. There was no statistically significant difference depending on the order of completion of the two tests which limits the bias of our study $(p=0.61)$.

\section{Discussion}

Our study showed the interest of the eMOVA test as a screening test for amblyopia in children from 3 to 8 years old. It showed its reliability with a correct agreement with the Rossano-Weiss test (ICC 0.43), 95\% correspondence for the best visual acuity and a mean difference in visual acuity of $0.06 \log$ MAR between the two tests. These results are good compared to those of studies that have developed similar tests $(12,13)$. The eMOVA test is reproducible (ICC 0.93) and simple. Indeed the understanding of the test was high (score of $4.8 / 5$ ) and the testability of $97 \%$ in our sample which is very good in comparison with the main tests having shown their good performance $(14,15)$. These rates are to be interpreted by taking into account the age of the study population, which varies considerably. Studies of only children under 10 are 
not the most common (16-23). Their comparison made it possible to highlight the speed of realization of the eMOVA test $(12,13)$.

The test was chosen as preferred by $87 \%$ of children and $80 \%$ of parents. The difficulty was less, as shown by the FLACC scale. The eMOVA test is fast, with an average duration of one minute, thus it avoids any risk related to LEDs exposure. The eMOVA test is inexpensive compared to the price of test projectors and Retinomax. EMOVA strengths are the measurement of angular visual acuity via Raskin's $\mathrm{E}$, its accessibility and the automation of the test. The mobility of the test and its possibility of realization by non-medical health professionals is a major step forward. The possibility of being self-directed at home by the child or his parents could increase screening capacity and at-home monitoring progress in the rehabilitation of amblyopia $(16,22)$. The computerization of the data may also have an epidemiological interest (24).

The eMOVA test, however, showed some limitations with a lower concordance for the lowest visual acuity, but these data are consistent with those in the literature for similar studies $(17,25,26)$. In our sample, only $16 \%$ of children using eMOVA had their first visit. There was $34 \%$ strabismus and the prevalence of amblyopia was $19 \%$ considering the Rossano-Weiss test as gold standard. These incidence of amblyopia and strabismus are much higher than those found in the literature $(1,16,27-44)$. This is explained because these children were visiting a specialized ophthalmic-pediatric center. This bias may limit the extrapolation of our results to screening conditions. In addition, most of the children included had already benefited from previous consultations. Only $16 \%$ of the children in our sample came for the first time. The remaining $84 \%$ were therefore trained in the Rossano-Weiss test, which can create a bias related to a learning effect. However our study has the merit of being a study of real life contrary to what one could find in the literature (12). The isolated optotype presentation decreases the contour interaction effect and may overestimate visual acuity compared to scales including a linear presentation of the optotypes. The eMOVA test presents the possible choices for pairing in groups of four, but the optotype to be recognized is presented in isolation. This phenomenon could help to explain the overestimation of visual acuity with the eMOVA test.

Several studies have sought to determine the optimal technical characteristics of tablets for the evaluation of visual acuity and to show the interest of these media (45-47). Further studies are needed to verify whether the visual acuity measurements obtained with the eMOVA test can be comparable on tablets of different models and brands.

The choice of gold standard can also be discussed. The correct level of concordance found in our study shows the lack of accuracy between the two tests but does not tell us about the test whose measurements are closest to reality. No visual acuity test is perfect and the Rossano-Weiss test has its own flaws. The eMOVA test should be compared to other scales of visual acuity and especially to the ETDRS scale to better define its limits.

Our study led to the development of a simple method for assessing visual acuity of children on tablets. It revealed a correct match of the eMova test with the reference method we use in common practice, the 
Rossano-Weiss test. This new test has been successfully submitted to children with a high rate of acceptability from both children and their parents. Further studies are needed to evaluate the value of this test on a larger scale.

\section{Abbreviations}

eMOVA = electronic Measurement Of Visual AcuityPDA= palmtop computerAMD = age macular degenerationFLACC scale $=$ Face Legs Activity Cry Consolability scaleICC $=$ intra-class correlation coefiicientETDRS scale $=$ Early Treatment Diabetic Retinopathy Study scale

\section{Declarations}

The study and data collection conformed to all local laws and were compliant with the principles of the Declaration of Helsinki. Local institutional review board approved our study.Parents' or legal guardian' and child's consent have been obtained.

The datasets used and/or analysed during the current study are available from the corresponding author on reasonable request.

The Authors declare that there is no conflict of interest and that they received no specific funding for this work.

EDF contributed to the main idea of the study. NS and AS participated in the design and implementation of the study. NS collected, analyzed and interpreted all of the data. CSS authorized the study and made its patients available for ophthalmic-pediatric consultations.All the authors approved the submitted version. The authors thank the team of orthoptists who helped carry out the tests and collect the data.

\section{References}

1. Arnold RW. Amblyopia risk factor prevalence. J Pediatr Ophthalmol Strabismus. août 2013;50(4):213-7.

2. Toy BC, Myung DJ, He L, Pan CK, Chang RT, Polkinhorne A, et al. Smartphone-based dilated fundus photography and near visual acuity testing as inexpensive screening tools to detect referral warranted diabetic eye disease. Retina Phila Pa. mai 2016;36(5):1000-8.

3. Coady P, Blumenkranz M, Fung A, Friedman N, Joffe E, Palanker D. Reading of portable electronic displays by patients with macular disease ( presentation at the American Academy of Ophtalmology congress) [Internet]. 2011. Disponible sur: https://www.digisight.net/fe/documents/Coady2011.pdf

4. Ye Y, Wang J, Xie Y, Zhong J, Hu Y, Chen B, et al. Global teleophthalmology with iPhones for real-time slitlamp eye examination. Eye Contact Lens. sept 2014;40(5):297-300.

5. Dorr M, Lesmes LA, Lu Z-L, Bex PJ. Rapid and reliable assessment of the contrast sensitivity function on an iPad. Invest Ophthalmol Vis Sci. 5 nov 2013;54(12):7266-73. 
6. Bodduluri L, Boon MY, Ryan M, Dain SJ. Normative values for a tablet computer-based application to assess chromatic contrast sensitivity. Behav Res Methods. 14 avr 2017;

7. Bhosai SJ, Amza A, Beido N, Bailey RL, Keenan JD, Gaynor BD, et al. Application of smartphone cameras for detecting clinically active trachoma. Br J Ophthalmol. oct 2012;96(10):1350-1.

8. Jeon ST, Hamid J, Maurer D, Lewis TL. Developmental changes during childhood in single-letter acuity and its crowding by surrounding contours. J Exp Child Psychol. déc 2010;107(4):423-37.

9. Pécherau A, Denis D, Speeg-Schatz C. Strabisme. Report of the French Society of Ophtalmology. Elsevier Masson. 2013.

10. Roth $A$, Gomez A, Pécherau A. La réfraction de l'oeil : du diagnostique à l'équipement optique. Atlas en ophtalmologie. Elsevier Masson. 2007.

11. Huurneman B, Boonstra FN. Assessment of near visual acuity in 0-13 year olds with normal and low vision: a systematic review. BMC Ophthalmol. 8 déc 2016;16(1):215.

12. Aslam TM, Parry NRA, Murray IJ, Salleh M, Col CD, Mirza N, et al. Development and testing of an automated computer tablet-based method for self-testing of high and low contrast near visual acuity in ophthalmic patients. Graefes Arch Clin Exp Ophthalmol Albrecht Von Graefes Arch Klin Exp Ophthalmol. mai 2016;254(5):891-9.

13. Ma DJ, Yang HK, Hwang J-M. Reliability and validity of an automated computerized visual acuity and stereoacuity test in children using an interactive video game. Am J Ophthalmol. juill 2013;156(1):195-201.e1.

14. Rice ML, Leske DA, Holmes JM. Comparison of the amblyopia treatment study HOTV and electronicearly treatment of diabetic retinopathy study visual acuity protocols in children aged 5 to 12 years. Am J Ophthalmol. févr 2004;137(2):278-82.

15. Kvarnström G, Jakobsson P. Is vision screening in 3-year-old children feasible? Comparison between the Lea Symbol chart and the HVOT (LM) chart. Acta Ophthalmol Scand. févr 2005;83(1):76-80.

16. Lan W, Zhao F, Li Z, Zeng J, Liu W, Lu J, et al. Validation and cost-effectiveness of a home-based screening system for amblyopia. Ophthalmology. juin 2012;119(6):1265-71.

17. Tofigh S, Shortridge E, Elkeeb A, Godley BF. Effectiveness of a smartphone application for testing near visual acuity. Eye Lond Engl. nov 2015;29(11):1464-8.

18. Shin YJ, Lee IB, Wee WR, Lee JH, Hwang J-M. A novel computerized visual acuity test for children. Korean J Ophthalmol KJO. juin 2013;27(3):194-8.

19. Phung L, Gregori NZ, Ortiz A, Shi W, Schiffman JC. Reproductibility and comparison of visual acuity obtained with sightbook mobile application to near card and snellen chart. Retina Phila Pa. mai 2016;36(5):1009-20.

20. Bastawrous A, Rono HK, Livingstone IAT, Weiss HA, Jordan S, Kuper $\mathrm{H}$, et al. Development and Validation of a Smartphone-Based Visual Acuity Test (Peek Acuity) for Clinical Practice and Community-Based Fieldwork. JAMA Ophthalmol. août 2015;133(8):930-7. 
21. Pathipati AS, Wood EH, Lam CK, Sáles CS, Moshfeghi DM. Visual acuity measured with a smartphone app is more accurate than Snellen testing by emergency department providers. Graefes Arch Clin Exp Ophthalmol Albrecht Von Graefes Arch Klin Exp Ophthalmol. juin 2016;254(6):1175-80.

22. Paysse EA, Camejo L, Hussein MAW, Coats DK. Parent-administered visual acuity testing: is it reliable and can it improve office efficiency? J AAPOS Off Publ Am Assoc Pediatr Ophthalmol Strabismus. août 2004;8(4):332-7.

23. Aslam TM, Tahir HJ, Parry NRA, Murray IJ, Kwak K, Heyes R, et al. Automated Measurement of Visual Acuity in Pediatric Ophthalmic Patients Using Principles of Game Design and Tablet Computers. Am J Ophthalmol. oct 2016;170:223-7.

24. Arora KS, Chang DS, Supakontanasan W, Lakkur M, Friedman DS. Assessment of a rapid method to determine approximate visual acuity in large surveys and other such settings. Am J Ophthalmol. juin 2014;157(6):1315-1321.e1.

25. Perera C, Chakrabarti R, Islam FMA, Crowston J. The Eye Phone Study: reliability and accuracy of assessing Snellen visual acuity using smartphone technology. Eye Lond Engl. juill 2015;29(7):888-94.

26. Zhang Z, Zhang S, Huang X, Liang L. A pilot trial of the iPad tablet computer as a portable device for visual acuity testing. J Telemed Telecare. janv 2013;19(1):55-9.

27. Robaei D, Rose K, Ojaimi E, Kifley A, Huynh S, Mitchell P. Visual acuity and the causes of visual loss in a population-based sample of 6-year-old Australian children. Ophthalmology. juill 2005;112(7):1275-82.

28. Lim HT, Yu YS, Park S-H, Ahn H, Kim S, Lee M, et al. The Seoul Metropolitan Preschool Vision Screening Programme: results from South Korea. Br J Ophthalmol. juill 2004;88(7):929-33.

29. Pai AS-I, Rose KA, Leone JF, Sharbini S, Burlutsky G, Varma R, et al. Amblyopia prevalence and risk factors in Australian preschool children. Ophthalmology. janv 2012;119(1):138-44.

30. Robaei D, Rose KA, Ojaimi E, Kifley A, Martin FJ, Mitchell P. Causes and associations of amblyopia in a population-based sample of 6-year-old Australian children. Arch Ophthalmol Chic III 1960. juin 2006;124(6):878-84.

31. Friedman DS, Repka MX, Katz J, Giordano L, Ibironke J, Hawse P, et al. Prevalence of amblyopia and strabismus in white and African American children aged 6 through 71 months the Baltimore Pediatric Eye Disease Study. Ophthalmology. nov 2009;116(11):2128-2134.e1-2.

32. Multi-ethnic Pediatric Eye Disease Study Group. Prevalence of amblyopia and strabismus in African American and Hispanic children ages 6 to 72 months the multi-ethnic pediatric eye disease study. Ophthalmology. juill 2008;115(7):1229-1236.e1.

33. Faghihi M, Ostadimoghaddam H, Yekta AA. Amblyopia and strabismus in Iranian schoolchildren, Mashhad. Strabismus. déc 2011;19(4):147-52.

34. Williams C, Northstone K, Howard M, Harvey I, Harrad RA, Sparrow JM. Prevalence and risk factors for common vision problems in children: data from the ALSPAC study. $\mathrm{Br} \mathrm{J}$ Ophthalmol. juill 2008;92(7):959-64. 
35. Chang C-H, Tsai R-K, Sheu M-M. Screening amblyopia of preschool children with uncorrected vision and stereopsis tests in Eastern Taiwan. Eye Lond Engl. déc 2007;21(12):1482-8.

36. He M, Huang W, Zheng Y, Huang L, Ellwein LB. Refractive error and visual impairment in school children in rural southern China. Ophthalmology. févr 2007;114(2):374-82.

37. Goh P-P, Abqariyah Y, Pokharel GP, Ellwein LB. Refractive error and visual impairment in school-age children in Gombak District, Malaysia. Ophthalmology. avr 2005;112(4):678-85.

38. Ohlsson J, Villarreal G, Sjöström A, Cavazos H, Abrahamsson M, Sjöstrand J. Visual acuity, amblyopia, and ocular pathology in 12- to 13-year-old children in Northern Mexico. J AAPOS Off Publ Am Assoc Pediatr Ophthalmol Strabismus. févr 2003;7(1):47-53.

39. Chia A, Dirani M, Chan Y-H, Gazzard G, Au Eong K-G, Selvaraj P, et al. Prevalence of amblyopia and strabismus in young singaporean chinese children. Invest Ophthalmol Vis Sci. juill 2010;51(7):3411-7.

40. Wang Y, Liang YB, Sun LP, Duan XR, Yuan RZ, Wong TY, et al. Prevalence and causes of amblyopia in a rural adult population of Chinese the Handan Eye Study. Ophthalmology. févr 2011;118(2):279-83.

41. Rosman M, Wong TY, Koh CLK, Tan DTH. Prevalence and causes of amblyopia in a population-based study of young adult men in Singapore. Am J Ophthalmol. sept 2005;140(3):551-2.

42. Elflein HM. [Amblyopia. Epidemiology, causes and risk factors]. Ophthalmol Z Dtsch Ophthalmol Ges. avr 2016;113(4):283-8.

43. Aldebasi YH. Prevalence of amblyopia in primary school children in Qassim province, Kingdom of Saudi Arabia. Middle East Afr J Ophthalmol. mars 2015;22(1):86-91.

44. Nowak MS, Gos R, Jurowski P, Smigielski J. Correctable and non-correctable visual impairment among young males: a 12-year prevalence study of the Military Service in Poland. Ophthalmic Physiol Opt J Br Coll Ophthalmic Opt Optom. juill 2009;29(4):443-8.

45. Livingstone I a. T, Tarbert CM, Giardini ME, Bastawrous A, Middleton D, Hamilton R. Photometric Compliance of Tablet Screens and Retro-llluminated Acuity Charts As Visual Acuity Measurement Devices. PloS One. 2016;11(3):e0150676.

46. Aslam TM, Murray IJ, Lai MYT, Linton E, Tahir HJ, Parry NRA. An assessment of a modern touchscreen tablet computer with reference to core physical characteristics necessary for clinical vision testing. J R Soc Interface. 6 juill 2013;10(84):20130239.

47. Black JM, Jacobs RJ, Phillips G, Chen L, Tan E, Tran A, et al. An assessment of the iPad as a testing platform for distance visual acuity in adults. BMJ Open. 20 juin 2013;3(6).

\section{Figures}




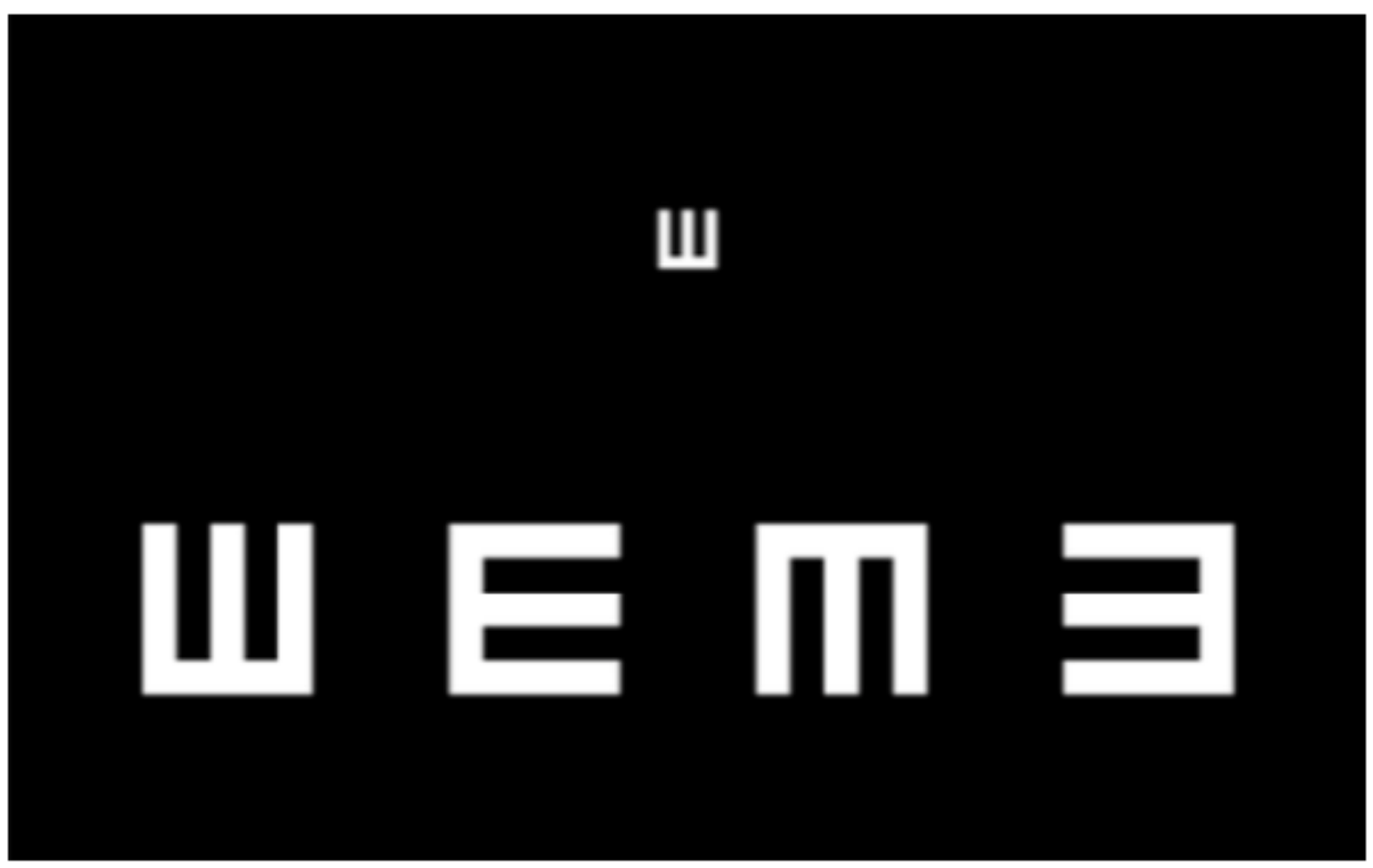

Figure 1

eMOVA test screen 


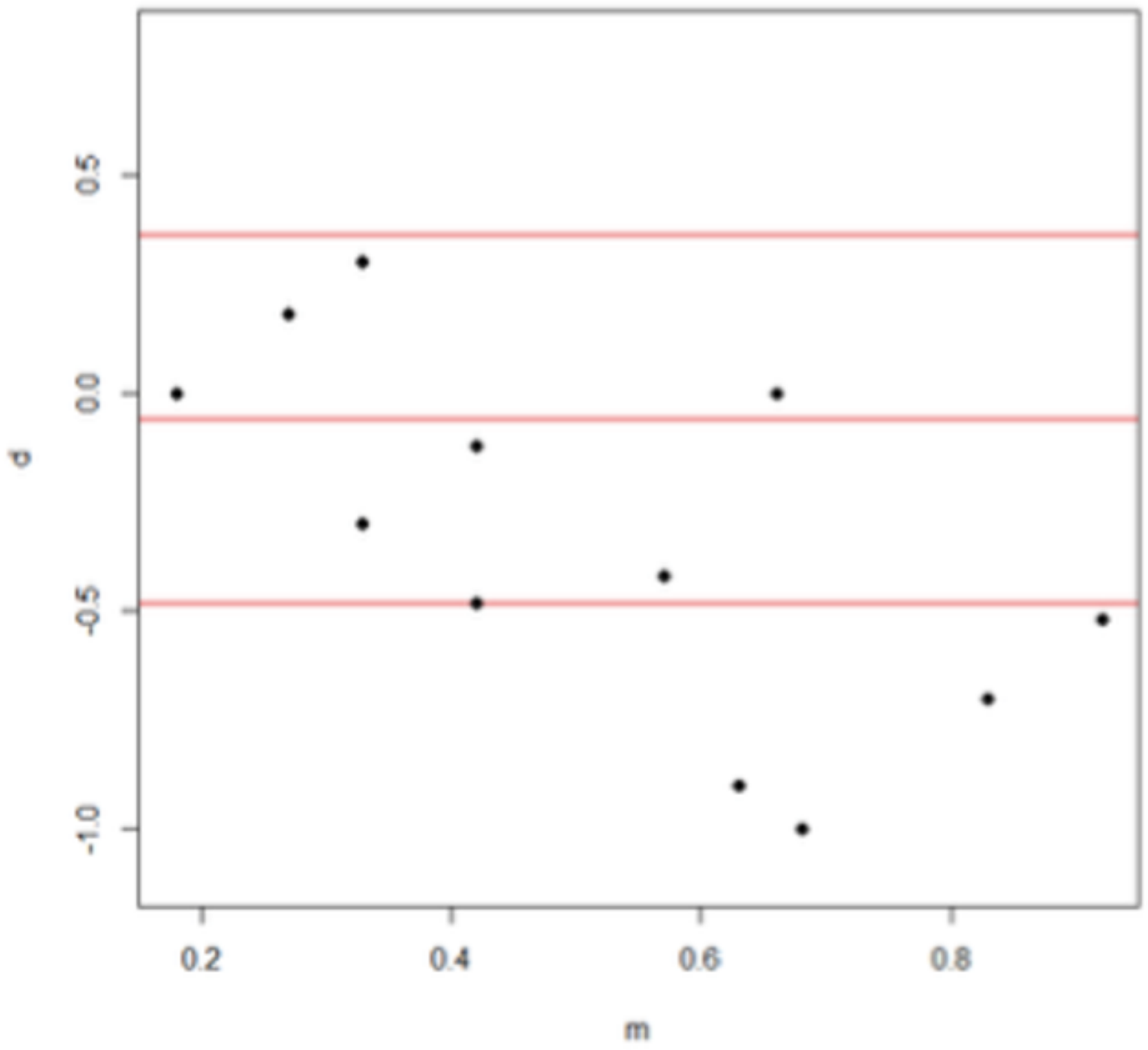

Figure 2

Bland and Altman analysis: quantitative concordance analysis for the visual acuity of the right eye (in $\log M A R)$. 


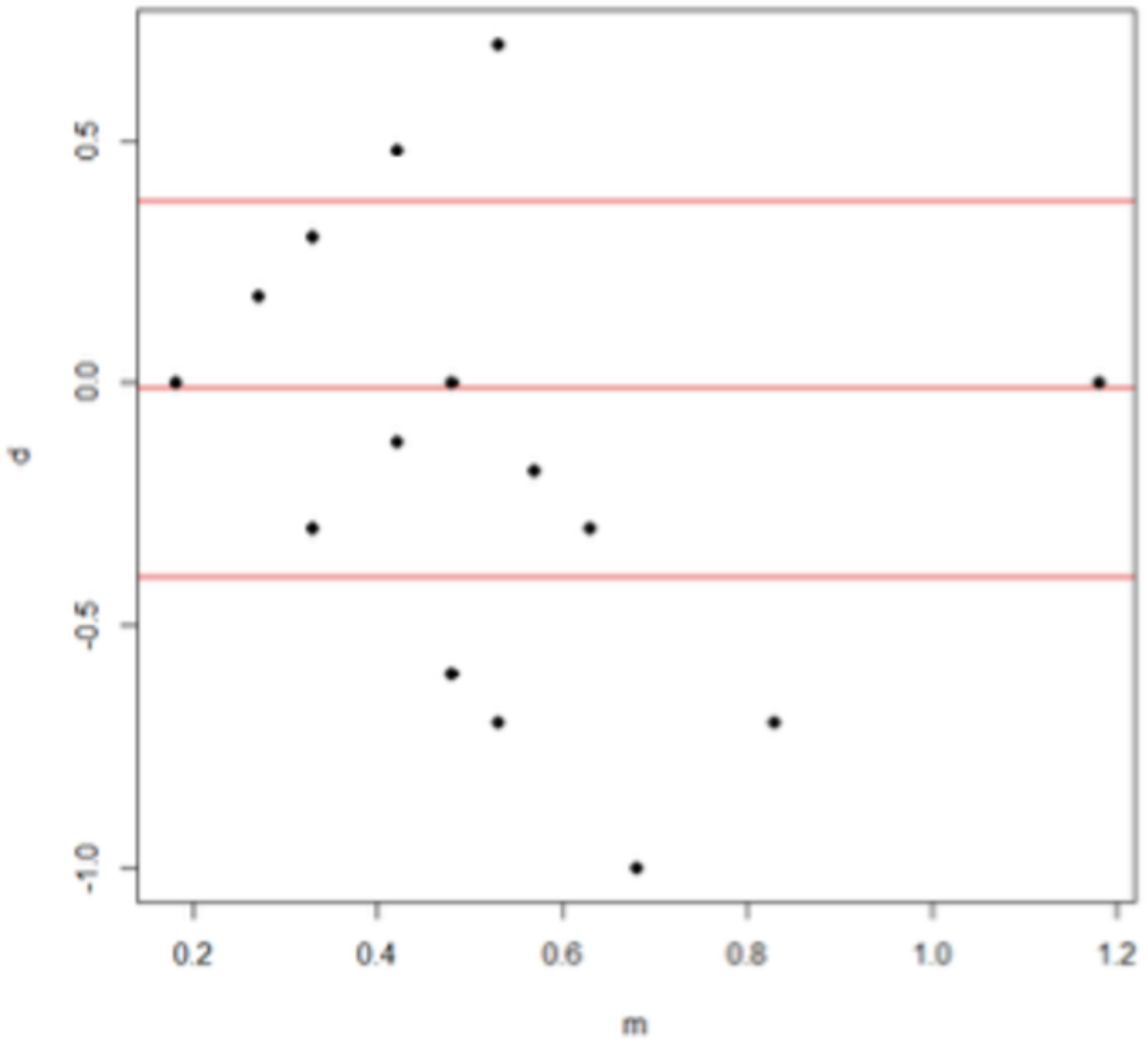

Figure 3

Bland and Altman analysis : quantitative concordance analysis for the visual acuity of the left eye (in $\log M A R)$. 